\title{
Wheat bran as a natural remedy for COVID-19
}

\author{
Khalid I. Elsayh ${ }^{1}$, Omnia El-Badawy ${ }^{2}$, Khaled Saad ${ }^{1, *}$ and Asmaa M. Zahran ${ }^{3}$ \\ ${ }^{1}$ Pediatric Department; ${ }^{2}$ Medical Microbiology and Immunology Department, Faculty of Medicine; \\ ${ }^{3}$ Department of Clinical Pathology, South Egypt Cancer Institute, Assiut University, Assiut, Egypt.
}

\begin{abstract}
COVID-19 severity is not only due to the viral infection but also due to the host immune responses. Destructive inflammatory responses are intensely implicated in airway damage. Besides, the massive release of cytokines, including interleukin 1 beta, interleukin 6 , and tumor necrosis factor-alpha by the immune system, results in a cytokine storm with an aggressive fulminant systemic inflammatory response, organ failure, and septic shock. Evidence suggests that the repressed antioxidant defense and overproduction of reactive oxygen species also have a role in COVID-19 pathogenesis. There is an urgent need for control measures against the overwhelming COVID-19 pandemic regarding antiviral and immune-modulating agents. Wheat bran [WB] has copious amounts of fiber, minerals, thiamine, vitamin B6, folate, and several phytochemicals as phenolic compounds. Wheat bran has antiinflammatory, immunomodulatory, and antioxidant properties. Our experience of using wheat bran as adjuvant therapy for acute lower respiratory tract infections showed that it was safe, well-tolerated, had fast and superb treatment responses, and improved the patients' general health. For that reason, we strongly praise using oral wheat bran as adjuvant therapy in COVID-19 cases.
\end{abstract}

KEYWORDS: COVID-19, wheat bran, anti-inflammatory agents, antioxidants, immunomodulation.

\footnotetext{
*Corresponding author: khaled.ali@med.au.edu.eg; ksaad8@yahoo.com
}

\section{INTRODUCTION}

Coronavirus disease 2019 (COVID-19) is caused by a novel coronavirus, severe acute respiratory syndrome coronavirus2 (SARS-CoV-2). The World Health Organization listed COVID-19 as a global public health emergency [1]. The clinical manifestations of SARS-CoV-2 vary from mild or asymptomatic disease to respiratory failure with acute respiratory distress syndrome (ARDS) that imposes mechanical ventilation and ICU [2]. Respiratory failure is the direct cause of death in COVID-19 patients. Destructive inflammatory responses are intensely implicated in airway damage. Besides, the massive release of cytokines, including interleukin 1 beta (IL-1 $\beta$ ), interleukin 6 (IL-6), and tumor necrosis factoralpha (TNF- $\alpha$ ) by the immune system, results in a cytokine storm with an aggressive fulminant systemic inflammatory response, organ failure, and septic shock [3-5]. Despite several trials, no suitable antiviral treatments or vaccines are recommended for COVID-19 [2]. There is an urgent need for control measures against the overwhelming COVID-19 pandemic regarding antiviral and immune-modulating agents and the further spread of SARS-CoV-2. Until these agents become available, an individual's immune status becomes the most influential factor of disease outcome [1].

\section{Immune dysregulation and inflammation in the context of COVID-19}

Earlier studies described that COVID-19 patients, especially those who are severe, showed a significant decrease in B-lymphocytes, $\mathrm{CD}^{+}$, 
$\mathrm{CD}^{+}$and $\mathrm{CD}^{+} \mathrm{T}$-lymphocytes, and natural killer cells $[1,6]$. T-cells' levels return to average values after 15-day treatment [1]. In the meantime, the inflammatory cytokines' levels were getting higher as the illness was getting worse [6].

Replication of cytopathic viruses, including SARS-CoV-2 [7], induces the death of virusinfected cells and may increase the inflammatory form of programmed cell death vascular leakage, called pyroptosis [8]. Pyroptosis promotes the plasma membrane's rupture and release of intracellular proinflammatory components [9], which likely elicit a subsequent inflammatory response [10]. Interleukin 1 beta (IL-1 $\beta$ ) is a critical cytokine released through pyroptosis during COVID-19 infection [11]. Upon detection of the virus, the macrophages and alveolar epithelial stressed cells release a wave of the proinflammatory chemokines and cytokines, including interferon-gamma (IFN $\gamma$ ), interleukin 6 (IL-6), monocyte chemotactic protein 1 (MCP1), and interferon gamma-induced protein 10 (IP-10) $[5,11]$ that strongly point to activation of T-helper-1 (Th1) cell function [12]. These cytokines and chemokines recruit immune cells to the lung, especially monocytes and $\mathrm{T}$ lymphocytes $[6,13]$, and, in most patients, they can resolve the infection. Nonetheless, an inadequate immune response in some patients triggers a cytokine storm leading to widespread lung inflammation. Large amounts of proinflammatory cytokines IL-1 $\beta$, IL-6, IL-12, IL-18, IL-33, interferon-alpha (IFN- $\alpha$ ), IFN- $\gamma$, TNF- $\alpha$, transforming growth factor-beta (TGF- $\beta$ ), and chemokines-CCL3, CCL2, CCL5, CXCL8, CXCL10, CXCL9, and others -prompts and sustains a fulminant systemic inflammatory response $[11,14-16]$. IL-6 plays a vital role in the cytokine storm's pathogenesis, and its level leaps over time and is positively related to disease severity [5, 17, 18]. Relatively higher IL-6 were detected in non-survivors than survivors [19]. Besides, elevated cytokines such as TNF- $\alpha$ can cause multi-organ failure and septic shock [20].

\section{Role of oxidative stress in the pathogenesis of COVID-19}

Little is known about COVID-19's relation with oxidative stress markers and the severity of the clinical disease. Though, some evidence suggests that repressed antioxidant defense and overproduction of reactive oxygen species have a central role in COVID-19 pathogenesis and the respiratory disease progression [21]. The uncontrolled inflammatory cell infiltration accompanying SARS-CoV-2 can itself mediate lung damage with the overproduction of proteases and reactive oxygen species (ROS). Together with the viral invasion itself, diffuse alveolar damage results in alveolar cell desquamation, hyaline membrane formation, and pulmonary edema [13, 22]. This leads to a less efficient exchange of gases, difficult breathing, and low arterial blood oxygen levels. It can also leave the lung more prone to secondary infections [4].

\section{COVID-19 immune-based therapy}

New immunosuppressive therapies heading for limiting the immunopathology accompanying SARS-CoV-2 are at different stages of development. Trials of corticosteroids [23], IL-6 antagonists [24], and others targeting granulocytemacrophage colony-stimulating factor (GM-CSF) [25] are currently being explored. One more new adjunctive therapy is cytosorb (CytoSorbents Corporation, 2020), which absorbs and decreases the circulating levels of a variety of cytokines, damage-associated molecular patterns (DAMPs), and pathogen-associated molecular patterns (PAMPs). Thalidomide, an immunomodulatory anti-inflammatory agent, is also currently being tested $[17,26]$. Tumor necrosis factor antagonism was recommended but still has not been used in SARS-CoV-2 [27].

\section{The rationale for using wheat bran as supportive therapy for COVID-19}

\subsection{Wheat bran composition}

Wheat, which is a grass plant, is the second main human food crop after rice. The wheat grain or 'caryopsis' is composed of several different portions: the germ (or embryo) $(2-3 \%$ of the grain), the starchy endosperm $(81-84 \%)$, which provides energy for germination, and the covering layers that constitute the wheat bran (14-16\%) The wheat bran layers include the thick cell-wall edaleurone layer, the hyaline layer, the viztesta, and the pericarp [28]. 
Wheat bran [WB] has copious amounts of fiber, minerals, thiamine, vitamin B6, vitamin E, folate, and several phytochemicals such as phenolic compounds [29]. Arabinoxylans constitutes approximately $55 \%$ of the nutritional fiber in wheat bran. Other fibers include cellulose $(10 \%)$, fructan (3\%), lignin (3\%), and $\beta$-glucan ( $2 \%)$. The ash represents $5.5-6.5 \%$ of the wheat bran. The wheat bran also comprises of around 5\% diand trisaccharides, e.g., raffinose and sucrose. Cellulose forms $30 \%$ of the wheat bran's cell wall. Cellulose, together with lignin and other fibers, forms lignocellulose, extremely resistant to degradation [30]. Arabinoxylans have potent antioxidative properties that are possibly due to the phenolic compounds attached to the arabinose residues [31]. It has recently been proposed that phenolic acids may prevent cardiovascular disorders and cancer by decreasing the oxidative cellular damage [32].

The protein is almost $15.2-16.9 \%$ of the wheat bran (14\% of the wheat kernel protein content). Wheat bran protein is primarily made up of aspartic and glutamic acids [33]. Furthermore, wheat bran contains lipids (5.5-5.6\%), most of which are phospholipids with some glycolipids. About half the lipids are unsaturated with 2 double bonds [34].

Wheat bran is an essential functional food ingredient with numerous positive health implications. It has a prebiotic effect on the colonic microflora by selectively boosting a number of beneficial colonic bacteria's growth. The wheat bran fermentation by intestinal microbiota generates short-chain fatty acids, e.g., butyrate, acetate, and propionate, potentially having positive health effects [35]. Arabinoxylans are the main component in the wheat brain responsible for refining numerous intestinal barrier functions with changes in microbiota composition [36].

\subsection{Antioxidant properties of wheat bran}

Plant extracts as natural antioxidants have gained broad global interest due to the concerns regarding the adverse effects of using chemical antioxidants [37]. Natural antioxidants are cheap, compatible with diet, and less harmful to humans. These factors lead to a drastic decrease in synthetic antioxidants in food products [38]. Wheat bran is a rich source of antioxidant phytochemicals such as phenolic acids, flavonoids, lignans, phytosterols, carotenoids, and tocopherols. Like ferulic acid, phenolic acid contents are the main determinants of wheat bran's antioxidant properties [39]. The total phenolic acid content in wheat bran is about $4.5 \mu \mathrm{g} / \mathrm{g}$ [40]. When delivered to the colon, phenolic compounds exert their potential beneficial health effects [41].

A previous study [42] has shown that wheat bran phenolic compounds, such as feruloylated oligosaccharides, guard human erythrocytes against oxidative damage induced by the free radicals. Another study [43] investigated the impact of supplemental wheat bran fibers on the antioxidant capacity and the antioxidantassociated signaling molecules of rat organs. They analyzed the free radical-scavenging competence against $\mathrm{O}_{2}{ }^{-}$and $\mathrm{OH}^{-}$radicals and activities of enzymatic and non-enzymatic (glutathione (GSH)) antioxidant capacities. They also assessed gene expression levels of antioxidant-related signaling molecules in the liver, spleen, and jejunum. Wheat bran fibers enhance antioxidant actions by lessening free radicals, raising enzymatic and nonenzymatic antioxidant activities, and significantly increasing enzymatic antioxidant messenger ribonucleic acid (mRNA) levels. Besides, supplementation of wheat bran fibers remarkably increased nuclear erythroid 2- factor 2 (Nrf2) and Kelch-like ECH-associated protein 1 (Keap-1), which is the core molecular target of cellular enzymatic related antioxidant inducers.

\subsection{The immune-modulatory potentials of wheat bran}

A previous study on the immune-modulatory effects of wheat Arabinoxylans in tumor-bearing mice showed that they potentially have an immunomodulatory effect and promote the overall immune functions [44]. Arabinoxylans were found to enhance the macrophage phagocytosis in tumor-bearing mice, possibly by acting like lipopolysaccharides (LPS) such as pathogenassociated molecular patterns (PAMPs) and attaching to toll-like receptors (TLRs) such as TLR-4 that are expressed on the surface of phagocytes [45]. Both lipopolysaccharides and 
arabinoxylans have standard structural features, including hexoses (like glucose and galactose) and C-3 branched polysaccharides [46].

Arabinoxylans also significantly enhanced sheep red blood cell-induced delayed-type hypersensitivity (DTH) reaction in tumor-bearing mice, signifying a role in the macrophage's activation. Arabinoxylans could considerably increase $\mathrm{T}$ and $\mathrm{B}$ cells' responsiveness and enhance cell-mediated and humoral immunity in tumor-bearing mice. Moreover, oral treatment with arabinoxylans promoted natural killer cells' cytotoxicity from splenocytes in tumor-bearing mice. A dose-dependent increase in IL-2 secretion in the blood serum of tumor-bearing mice was also observed after treatment with arabinoxylans [44]. IL-2 is known to boost the proliferation of $\mathrm{T}$ cells, B cells, natural killer cells, and monocytes and increase the natural killer and $\mathrm{T}$ cells' cytotoxicity [47]. Furthermore, treatment with arabinoxylans increased bone-marrow cellularity and peripheral white blood cells' count in tumorbearing mice, which designate their potential effects on the stimulation of hematopoiesis and stem cell proliferation [44].

\subsection{Anti-inflammatory effects of wheat bran}

Excess proinflammatory cytokines, such as IL-1 $\beta$, IL-6, and TNF- $\alpha$ secreted by T-helper- 1 cells, can harm the host, altering the production of other cytokines, chemokines, and adhesion molecules [48]. IL-10 an anti-inflammatory cytokine secreted by T-helper- 2 cells is a central regulator of inflammatory responses [49]. Transforming growth factor-beta (TFG- $\beta$ ) is also a cytokine crucial in regulating the immune system [50]. Both IL-10 and TFG- $\beta$ suppress the T-cell effector responses [51]. An earlier study on pigs indicated that supplemental dietary fibers induce a cellular immune response by regulating cytokine immunomodulation [52]. Previous research in animals reported that wheat bran fibers were more useful in controlling the inflammatory response than other diets. Wheat bran fibers enhanced the upregulation of mRNA gene of anti-inflammatory cytokines IL-10 and TGF- $\beta$ and downregulation of the mRNA gene of proinflammatory cytokines IL- 6 and TNF- $\alpha$ in animal jejunum, liver, and spleen [43, 49]. Other studies reported that macrophage pre-treatment with ferulic acid reduced the inflammation induced by lipopolysaccharides [53, 54]. Wheat bran ferulic acid inhibited the secretion of inflammatory cytokines IL-6 and TNF- $\alpha$ detected in lipopolysaccharide-stimulated cells [55].

\subsection{Our clinical experience in using wheat bran as adjuvant therapy in patients with acute lower respiratory tract infection}

In the last few years, there has been a surge of increasing incidence of lower respiratory tract infections in infants, children, and adults, especially in the winter. Many patients had prolonged distressing cough that, in some cases, persisted for several days, even more than one month. Because the hospital was under increased pressure to maintain healthcare capacity for the more severely ill patients, mild and, on some occasions, moderate cases were discharged home. Due to wheat bran's previously mentioned health benefits, safety, and easy administration, it was a suitable adjuvant therapy, especially for those who had completed their treatment at home.

A cohort of 300 cases of different ages and sex, complaining of acute lower respiratory tract infections refractory to the standard first-line measures, were treated with adjuvant wheat bran (results not published yet). Patients were given oral wheat bran; 2 teaspoons in $200 \mathrm{ml}$ water, 2 to 3 times a day until complete recovery in conjunction with the standard treatment measures. In infants and cases in which oral administration was not possible, wheat bran was given via rectal enema. We developed a simple way for wheat bran enema administration, which is safe, feasible, and accepted by the parents. The benefits of wheat bran and the technique were explained to the patients or their parents. Participation was entirely voluntary, and they were able to withdraw at any time. All patients treated with adjuvant wheat bran showed a good response from the first day. This was encouraging for the mothers to use the wheat bran enema more frequently until full recovery, which in most cases took nearly five to seven days. Also, upon using adjuvant wheat bran therapy (oral or rectal enema), we noticed a fall of temperature in patients who presented with highgrade fever. Furthermore, patients with acute and 
persistent gastroenteritis showed quick improvement after receiving adjuvant wheat bran (either oral or rectal enema). Generally, wheat bran was safe, well-tolerated, showed fast and superb treatment responses, and improved general health.

\section{CONCLUSION}

In conclusion, wheat bran is one of the fibers wealthiest in vitamins, minerals, and bioactive compounds. It has anti-inflammatory, immunomodulatory, and antioxidant properties. It showed promising results in treating patients with acute respiratory tract infections, of different age groups. For that reason, we strongly praise using oral wheat bran as adjuvant therapy in COVID-19 cases.

\section{COMPLIANCE WITH ETHICAL STANDARDS}

\section{CONFLICT OF INTEREST STATEMENT}

There is no conflict of interest for this study.

\section{FUNDING}

No specific funding was secured for this article.

\section{REFERENCES}

1. He, R., Lu, Z., Zhang, L., Fan, T., Xiong, R., Shen, X., Feng, H., Meng, H., Lin, W., Jiang, W. and Geng, Q. 2020, J. Clin. Virol., 127, 104361 .

2. Cascella, M., Rajnik, M., Cuomo, A., Dulebohn, S. C. and Di Napoli, R. 2020, Statpearls [Internet]: StatPearls Publishing.

3. Reilly, J. P., Anderson, B. J., Hudock, K. M., Dunn, T. G., Kazi, A., Tommasini, A., Charles, D., Shashaty, M. G., Mikkelsen, M. E., Christie, J. D. and Meyer, N. J. 2004, Clin. Exp. Immunol., 136, 95.

4. Tay, M. Z., Poh, C. M., Rénia, L., MacAry, P. A. and Ng, L. F. P. 2020, Nat. Rev. Immunol., 20(6), 363.

5. Zhang, B., Zhou, X., Qiu, Y., Song, Y., Feng, F., Feng, J., Song, Q., Jia, Q. and Wang, J. 2020, PLoS One, 15(7), e0235458.

6. Xu, B., Fan, C. Y., Wang, A. L., Zou, Y. L., Yu, Y. H., He, C., Xia, W. G., Zhang, J. X. and Miao, Q. 2020, J. Infect., 81(1), e51.
7. Park, W. B., Kwon, N. J., Choi, S. J., Kang, C. K., Choe, P. G., Kim, J. Y., Yun, J., Lee, G. W., Seong, M. W., Kim, N. J., Seo, J. S. and Oh, M. D. 2020, J. Korean Med. Sci., 35(7), e84.

8. Chen, I. Y., Moriyama, M., Chang, M. F. and Ichinohe, T. 2019, Front. Microbiol., 10, 50.

9. Bergsbaken, T., Fink, S. L. and Cookson, B. T. 2009, Nat. Rev. Microbiol., 7, 99.

10. Yang, M. 2020, SSRN: http://dx.doi.org/ $10.2139 /$ ssrn. 3527420

11. Huang, C., Wang, Y., Li, X., Ren, L., Zhao, J., Hu, Y., Zhang, L., Fan, G., Xu, J., Gu, X., Cheng, Z., Yu, T., Xia, J., Wei, Y., Wu, W., Xie, X., Yin, W., Li, H., Liu, M., Xiao, Y. and Cao, B. 2020, Lancet, 395, 497.

12. Huang, K. J., Su, I. J., Theron, M., Wu, Y. C., Lai, S. K., Liu, C. C. and Lei, H. Y. 2005, J. Med. Virol., 75(2), 185.

13. Tian, S., Hu, W., Niu, L., Liu, H., Xu, H. and Xiao, S. Y. 2020, J. Thorac. Oncol., 15(5), 700.

14. Cameron, M. J., Bermejo-Martin, J. F., Danesh, A., Muller, M. P. and Kelvin, D. J. 2008, Virus Research, 133, 13-19.

15. Channappanavar, R. and Perlman, S. 2017, Semin. Immunopathol., 39(5), 529.

16. Williams, A. E. and Chambers, R. C. 2014, Am. J. Physiol. Lung Cell Mol. Physiol., 306(3), L217.

17. Chen, L., Liu, H. G., Liu, W., Liu, J., Liu, K., Shang, J., Deng, Y. and Wei, S. 2020, Chin. J. Tubercul. Respirat. Dis., 43, E005.

18. McGonagle, D., Sharif, K., O’Regan, A. and Bridgewood, C. 2020, Autoimmun. Rev., 19(6), 102537.

19. Zhou, F., Yu, T., Du, R., Fan, G., Liu, Y., Liu, Z., Xiang, J., Wang, Y., Song, B., Gu, X., Guan, L., Wei, Y., Li, H., Wu, X., Xu, J., Tu, S., Zhang, Y., Chen, H. and Cao, B. 2020, Lancet, 395(10229), 1054.

20. Ruan, Q., Yang, K., Wang, W., Jiang, L. and Song, J. 2020, Inten. Care Med., 46(5), 846.

21. Delgado-Roche, L. and Mesta, F. 2020, Arch. Med. Res., 51(5), 384.

22. Xu, Z., Shi, L., Wang, Y., Zhang, J., Huang, L., Zhang, C., Liu, S., Zhao, P., Liu, H., Zhu, L., Tai, Y., Bai, C., Gao, T., Song, J., Xia, P., Dong, J., Zhao, J. and Wang, F. S. 2020, Lancet Respir. Med., 8(4), 420. 
23. Ye, Z., Wang, Y., Colunga-Lozano, L. E., Prasad, M., Tangamornsuksan, W., Rochwerg, B., Yao, L., Motaghi, S., Couban, R. J., Ghadimi, M., Bala, M. M., Gomaa, H., Fang, F., Xiao, Y. and Guyatt, G. H. 2020, CMAJ, 192(27), E756.

24. Liu, A. 2020, https://www.fiercepharma. com/pharma-asia/china-turns-roche-arthritisdrug-actemra-against-covid-19-newtreatment-guidelines

25. Izana Bioscience. 2020, Izana Bioscience https://izanabio.com/initiation-of-twocentre-compassionate-use-study-involvingnamilumab-in-the-treatment-of-individualpatients-with-rapidly-worsening-covid-19infection-in-italy/

26. Xia, J. 2020, https://clinicaltrials.gov/ct2/ show/NCT04273581

27. Tobinick, E. 2004, Curr. Med. Res. Opin., 20(1), 39.

28. Tegge, G. 1988, American Association of Cereal Chemists [AACC, 3340 Pilot Knob Road, St. Paul, MN 55121, USA], Vol. I, p 562.

29. Shewry, P. R. 2009, J. Exp. Bot., 60(6), 1537.

30. Esposito, F., Arlotti, G., Bonifati, A. M., Napolitanoa, A., Vitalec, D. and Fogliano, V. 2005, Food Res. Internat., 38, 1167.

31. Maki, K. C., Gibson, G. R., Dickmann, R. S., Kendall, C. W., Chen, C. Y., Costabile, A., Comelli, E. M., McKay, D. L., Almeida, N. G., Jenkins, D., Zello, G. A. and Blumberg, J. B. 2012, Nutrition, 28, 1115.

32. Dai, J. and Mumper, R. J. 2020, Molecules, 15,7313 .

33. Mateo Anson, N., Hemery, Y. M., Bast, A. and Haenen, G. R. 2012, Food \& Function, 3(4), 362.

34. Chung, O. K., Ohm, J. B., Ram, M. S., Park, S. H. and Howitt, C. A. 2009, Wheat; Fourth Edition, 363: AACC International Press.

35. Costabile, A., Klinder, A., Fava, F., Napolitano, A., Fogliano, V., Leonard, C., Gibson, G. R. and Tuohy, K. M. 2008, Br. J. Nutr., 99, 110.

36. Aoe, S., Nakamura, F. and Fujiwara, S. 2018, Nutrients, 10(12), 1980.

37. Azizkhani, M. and Zandi, P. 2009, Internat. J. Nutrit. Food Eng., 3, 1.
38. Anbudhasan, P., Surendraraj, A., Karkuzhali, S. and Sathishkumaran, P. 2014, Internat. J. Food Nutrit. Sci., 3, 225.

39. Belobrajdic, D. P. and Bird, A. R. 2013, Nutr. J., 12, 62.

40. Babu, C. R., Ketanapalli, H., Beebi, S. K. and Kolluru, V. C. 2018, Adv. Biotechnol. Microbiol., 9, 1.

41. Vitaglione, P., Napolitano, A. and Fogliano, V. 2008, Trends Food Sci. Technol., 19, 451.

42. Wang, J., Sun, B., Cao, Y. and Tian, Y. 2009, Food Chem. Toxicol., 47, 1591.

43. Fang, T, Wu, X, Cao, W, Jia, G., Zhao, H., Chen, X., Wu, C., Tang, J., Wang, J. and Liu, G. 2017, RSC Advances, 7, 19611-620.

44. Cao, L., Liu, X., Qian, T., Sun, G., Guo, Y., Chang, F., Zhou, S. and Sun, X. 2011, Int. J. Biol. Macromol., 48(1), 160.

45. Shen, T., Wang, G., You, L., Zhang, L., Ren, H., Hu, W., Qiang, Q., Wang, X., Ji, L., Gu, Z. and Zhao, X. 2017, Food Nutr. Res., 61(1), 1344523.

46. Miller, S. I., Ernst, R. K. and Bader, M. W. 2005, Nat. Rev. Microbiol., 3, 36.

47. Asano, Y., Kaneda, K., Hiragushi, J., Tsuchida, T. and Higashino, K. 1997, Cancer Immunol. Immunother., 45(2), 63.

48. Wieser, V., Moschen, A. R. and Tilg, H. 2013, Arch. Immunol. Ther. Exp. (Warsz), $61,119$.

49. Opal, S. M. and DePalo, V. A. 2020, Chest, $117,1162$.

50. Letterio, J. J. and Roberts, A. B. 1998, Annu. Rev. Immunol., 16, 137.

51. Palomares, O., Martín-Fontecha, M., Lauener, R., Traidl-Hoffmann, C., Cavkaytar, O., Akdis, M. and Akdis, C. A. 2014, Genes Immun., 15, 511.

52. Chen, H., Mao, X., He, J., Yu, B., Huang, Z., Yu, J., Zheng, P. and Chen, D. 2013, Br. J. Nutr., 110, 1837.

53. Lampiasi, N. and Montana, G. 2016, Immunobiol., 221, 486.

54. Nile, S. H., Ko, E. Y., Kim, D. H. and Keum, Y. S. 2016, Rev. Bras Farmacogn., 26, 50.

55. Yin, Z. N., Wu, W. J., Sun, C. Z., Liu, H. F., Chen, W. B., Zhan, Q. P., Lei, Z. G., Xin, X., Ma, J. J., Yao, K., Min, T., Zhang, M. M. and Wu, H. 2019, Biomed. Environ. Sci., 32(1), 11. 